\title{
Impact of applying brief educational program on nurses knowledge, attitude, and practices toward pain management
}

\author{
Shalabia EL-Sayed Abozeid ${ }^{1 *}$, Mahmoud Al-Kalaldeh ${ }^{2}$, Omar Al-Tarawneh ${ }^{3}$ \\ ${ }^{I}$ Assistant Professor in Medical Surgical Nursing, Faculty of Nursing, Assiut University, Egypt \\ ${ }^{2}$ Assistant Professor, Critical care nursing, Faculty of Nursing, Al Zaytoonah University, Amman-Jordan \\ ${ }^{3}$ Omar Mohamad Al-Tarawneh RN.Quality Coordinator, Al.karak hospital-Jordan \\ *Corresponding author E-mail: shalabia.abozead@yahoo.com
}

\begin{abstract}
Background: The role of pain education is well established in improving knowledge and attitude towards the adherence to pain assessment and management.

Methods: A brief pain education program was delivered to assess nurses' knowledge and attitude towards pain assessment and management. The "KASRP" scale was used at three phases; pre, post, and three months' follow-up phases. Subsequent eight months observation on using pain assessment sheets was also performed.

Results: One hundred and four nurses were assessed at the beginning, followed by 92 at the immediate post-test, and 70 at the follow-up. Although nurses scored lowest in having knowledge and attitudes prior to the program, a significant improvement was evident after delivering pain education. In addition, nurses' competency in pain assessment was maintained over the three months of assessment. Younger nurses with shorter clinical experience were found more reactive to the program than older nurses.
\end{abstract}

Conclusions: A brief nurse-driven pain education has improved nurses' knowledge and attitude towards pain management.

Keywords: Attitudes; Knowledge; KASRP; Nurses; Pain Education.

\section{Introduction}

Pain is an inherently subjective symptom which is frequently experienced in the acute illnesses and is one of the symptoms that patients dread from (Jain, Yeluri et al. 2012). Undertaking pain management aims to avoid negative physiological and psychological consequences (Twycross 2007). As pain assessment is a responsibility of nurses, nurses are required to use the appropriate assessment measures and intervene accordingly (Kastrup, von Dossow et al. 2009). Untreated pain may result in multi-system complications and the development of chronic unrelenting pain leading to impaired body functioning, disturbed quality of life and well-being (Kehlet, Jensen et al. 2006; Dunwoody, Krenzischek et al. 2008). Many patients experience significant pain during hospitalization. For example, more than $30 \%$ of ICU patients suffer from pain at rest, and more than 50\% complain from pain during routine care, such as changing position, endotracheal suctioning, and wound care (Puntillo, White et al. 2001; Chanques, Sebbane et al. 2007).

Lack of knowledge about pain and its features is a common barrier to effective pain management (Ware, Bruckenthal et al. 2011). Ineffective pain managements by nurses and nurses' reluctance to embrace all dimensions regarding pain is problematic (Hirsh, Jensen et al. 2010). For instance, nurses were found had inadequate knowledge about opioid analgesic drugs (Schafheutle, Cantrill et al. 2001). They may develop different attitudes towards pain, thereby, they may subjectively judge the level of a patient's pain based on rituals or personal opinion (Schafheutle, Cantrill et al. 2001). Since most of the pain is undetectable, the use of these unreliable indicators may add complexity to pain assessment (Ware, Bruckenthal et al. 2011). This situation creates further challenge to nurses who need to consider other alternatives for pain management (Herr, Coyne et al. 2011; Fraser, Devlin et al. 2013).

There is an increasing demand on understanding patient's perception and reactions to pain along with understanding factors triggering, aggravating, and alleviating the intensity of experiencing pain (Apfelbaum, Chen et al. 2003). Nursing curriculums are criticized to have inadequate components of pain assessment and management which in eventual leads to ineffective nursing knowledge and performance (Abed El-Rahman, Kalaldeh et al. 2013).

This study aimed to assess the impact of a brief nurse-centered pain education program on nurses' knowledge and attitude towards pain assessment and pain management in the hospitalized patients.

\section{Methodology}

This pretest-posttest study measured changes in nurses' knowledge and attitudes towards pain assessment and management before and after the delivery of a brief pain education. Nurses working in Ma`an Governmental Hospital, in the south of Jordan were the study participants. Eligibility criteria included all nurses who provide bedsides care whether in the medical or surgical wards, and have a clinical experience more than six months. The number of nurses who were found eligible for participation was 153 nurses. Pain education was delivered by the first researcher (SA) who holds the doctoral degree in nursing and a specialty of pain education. The study assessed nurses' knowledge and attitudes towards 
pain as follows: before the intervention, immediately after the intervention, and three months follow-up after the intervention using a self-administered questionnaire. Data collection carried out in the period between April 2013 and July 2013. Ethical approval was obtained from Jordanian Ministry of Health and the hospital administrator. Participants' consent was obtained at the early stage of the study including the steps of ensuring confidentiality and anonymity. A pilot study was carried out on ten nurses prior to data collection to assess the clarity of the study instruments.

\section{Instruments}

A self-administered questionnaire was designed to include the following elements:

1) Personal demographic data including past experience of pain management.

2) Nurses' Knowledge and Attitudes Survey Regarding Pain (KASRP) (Betty Ferrell revised 2012.). Some items of the KASRP were removed from this study according to their relevance to nursing practice in Jordan. The scale used consisted of the following components: pain knowledge and attitude (15 items), pain assessment (eight items), and pain intervention (two case studies). Items related to knowledge and attitude were scored true or false, while items related to pain assessment and pain intervention were multiple-choice questions The total score of attitude and knowledge scale ranged from 0 30 , in which scores above 20 indicate good knowledge and attitudes toward pain and scores below 15 indicate poor knowledge and attitudes. This instrument was already checked for validity and reliability (Test-retest reliability: $r>.80$ ) and was used in different context successfully (alpha $r>.70$ ) (Betty Ferrell revised 2012.). The time estimated for completing the study instruments was 15-20 minutes.

3) The last source of data included counting the number of pain assessment charts used in this hospital over duration of eight months starting from the beginning of the study (from April 2013 to February 2014). The number of pain assessment sheets used was compared to the number of admitted patients in this hospital month-by-month.

\section{Pain education program}

This brief pain education program included five hours interactive learning session directed towards nurses who are working in Ma`an Governmental Hospital. The program consisted of a formal lecture and group discussions about pain assessment and pain management assisted by case studies. Materials and case studies were taken from "PainEDU Manual" ( $4^{\text {th }}$ edition, 2010) which is a comprehensive pain resource form heath care providers (16). After the session, short videos of adult and pediatric scenarios about pain managements were also provided. To ensure maximum benefits, a practice on pain assessment was performed on selected case studies and discussed later within the group. Nurses participated in the program were divided into three groups at different times according to their convenience. At the end of the session, each participant was given a notebook which included all information, guidelines, and practices delivered in the program.

\section{Data analysis}

Data was entered into the Statistical Package for Social Science (SPSS) software (version 17). Both descriptive and inferential statistics were used to describe data into categories, identify differences in the level of knowledge and attitude at different study phases. Factors affecting nursing knowledge and attitudes towards pain management were also explored. Chi-square, t-test, and the analysis of variance (ANOVA) were used to find differences. The multiple-hierarchal regression was used to assess factors affecting knowledge and attitude towards pain management.

\section{Results}

\subsection{Participants' demographics}

One hundred and four nurses participated in the study. This number has changed over the study duration to be 92 participants at the post-test and 70 participants at the follow-up phase considering $11.5 \%$ and $32.5 \%$ attrition rates, respectively. Table 1 shows the demographic characteristics of participants at the pre-test phase of the study. The majority of participants $(72.1 \%)$ aged between 18 28 years old and $64.4 \%$ of them were female nurses while $35.6 \%$ were male nurses. It was also evident that the majority hold the bachelor degree of nursing (91.3\%) and most of them (74.0\%) had clinical experience less than one year. All participants claimed no pain training received previously (Table 1 ).

Table 1: Participants' Demographic Data

\begin{tabular}{|c|c|c|c|c|}
\hline Variable & & Frequency & Percent $\%$ & $\begin{array}{l}\mathrm{P} \\
\text { value }\end{array}$ \\
\hline \multirow[t]{4}{*}{ Age } & $18-28$ years & 75 & $72.1 \%$ & \multirow{3}{*}{$<0.001$} \\
\hline & 29-35 years & 25 & $24.0 \%$ & \\
\hline & $36-42$ years & 4 & $3.9 \%$ & \\
\hline & Total & 104 & $100 \%$ & \\
\hline \multirow[t]{3}{*}{ Sex } & Male & 37 & $35.6 \%$ & \multirow{2}{*}{0.003} \\
\hline & Female & 67 & $64.4 \%$ & \\
\hline & Total & 104 & $100 \%$ & \\
\hline \multirow[t]{4}{*}{ Professional Degree } & $\begin{array}{l}\text { Registered } \\
\text { nurse }\end{array}$ & 95 & $91.3 \%$ & \multirow{3}{*}{$<0.001$} \\
\hline & $\begin{array}{l}\text { Associate } \\
\text { nurse }\end{array}$ & 8 & $7.7 \%$ & \\
\hline & $\begin{array}{l}\text { Assistant } \\
\text { nurse }\end{array}$ & 1 & $1 \%$ & \\
\hline & Total & 104 & $100 \%$ & \\
\hline \multirow[t]{4}{*}{ Experience } & $<1$ year & 77 & $74.0 \%$ & \multirow{3}{*}{$<0.001$} \\
\hline & $1-3$ years & 34 & $23.1 \%$ & \\
\hline & 4-7 years & 3 & $2.9 \%$ & \\
\hline & Total & 104 & $100 \%$ & \\
\hline \multirow{3}{*}{$\begin{array}{l}\text { Previous Pain Man- } \\
\text { agement Training }\end{array}$} & Yes & 0 & $0 \%$ & \\
\hline & No & 104 & $100 \%$ & \\
\hline & Total & 104 & $100 \%$ & \\
\hline
\end{tabular}

\subsection{Assessment of knowledge and attitude to pain}

Table 2 shows results of nurses' knowledge and attitudes to pain which includes the percentages of nurses who selected the correct answers. All knowledge and attitude queries were reported at the three phases of the study. As shown in the table, nurses showed low scores of knowledge and attitudes at the pre-test phase. In the immediate post-test assessment, nurses showed a significant improvement in their knowledge and attitudes towards pain as appeared in the all listed questions. However, these scores declined slightly after three months of program follow-up although the percentages of corrected answers in this phase were still significantly higher than those in the early stage.

Similarly, nurses showed improvements in pain assessment tasks likewise the previous section. Table 3 shows the results of multiple choice questions and case studies regarding pain assessment. It was apparent that nurses' responses to all questions in the pre-test phase was at the lowest scores compared to the significant higher scores in the post-test and follow-up. However, all responses were not significantly retracted at the follow-up phase. 
Table 2: Assessing Knowledge and Attitude towards Pain

\begin{tabular}{|c|c|c|c|c|c|}
\hline & $\begin{array}{l}\text { Questions } \\
\text { (Percentages are based on } \\
\text { the correct answers) }\end{array}$ & $\begin{array}{l}\text { Pre-test } \\
(n=104)\end{array}$ & $\begin{array}{l}\text { Post- } \\
\text { test } \\
(\mathrm{n}=92)\end{array}$ & $\begin{array}{l}\text { Follow- } \\
\text { up } \\
(\mathrm{n}=70)\end{array}$ & Sig. \\
\hline 1 & $\begin{array}{l}\text { Vital signs are always } \\
\text { reliable indicators of the } \\
\text { intensity of a patient's } \\
\text { pain. }\end{array}$ & $10.6 \%$ & $95.6 \%$ & $49.0 \%$ & $<0.001$ \\
\hline 2 & $\begin{array}{l}\text { Because their nervous } \\
\text { system is underdevel- } \\
\text { oped, children under two } \\
\text { years of age have de- } \\
\text { creased pain sensitivity } \\
\text { and limited memory of } \\
\text { painful experiences. }\end{array}$ & $43.3 \%$ & $76.0 \%$ & $53.8 \%$ & $<0.001$ \\
\hline 3 & $\begin{array}{l}\text { Patients who can be } \\
\text { distracted from pain } \\
\text { usually do not have se- } \\
\text { vere pain. }\end{array}$ & $10.6 \%$ & $71.2 \%$ & $57.7 \%$ & $<0.001$ \\
\hline 4 & $\begin{array}{l}\text { Patients may sleep in } \\
\text { spite of severe pain. }\end{array}$ & $40.4 \%$ & $79.8 \%$ & $63.5 \%$ & $<0.001$ \\
\hline 5 & $\begin{array}{l}\text { Respiratory depression } \\
\text { rarely occurs in patients } \\
\text { who have been receiving } \\
\text { stable doses of opioids } \\
\text { over a period of months. }\end{array}$ & $38.5 \%$ & $74.0 \%$ & $58.7 \%$ & $<0.001$ \\
\hline 6 & $\begin{array}{l}\text { Combining analgesics } \\
\text { that work by different } \\
\text { mechanisms (e.g., com- } \\
\text { bining an NSAID with an } \\
\text { opioid) may result in } \\
\text { better pain control with } \\
\text { fewer side effects than } \\
\text { using a single analgesic } \\
\text { agent. }\end{array}$ & $41.3 \%$ & $66.3 \%$ & $54.8 \%$ & $<0.001$ \\
\hline 7 & $\begin{array}{l}\text { The usual duration of } \\
\text { analgesia of } 1-2 \text { mg mor- } \\
\text { phine IV is } 4-5 \text { hours. }\end{array}$ & $10.6 \%$ & $79.8 \%$ & $58.7 \%$ & $<0.001$ \\
\hline 8 & $\begin{array}{l}\text { Opioids should not be } \\
\text { used in patients with a } \\
\text { history of substance } \\
\text { abuse. }\end{array}$ & $39.4 \%$ & $72.1 \%$ & $53.8 \%$ & $<0.001$ \\
\hline 9 & $\begin{array}{l}\text { There is a specific dosage } \\
\text { for Morphine, if exceeds, } \\
\text { the medication is no } \\
\text { longer to be effective. } \\
\text { Elderly patients cannot }\end{array}$ & $51.0 \%$ & $81.7 \%$ & $61.5 \%$ & $<0.001$ \\
\hline 10 & $\begin{array}{l}\text { tolerate opioids for pain } \\
\text { relief. }\end{array}$ & $44.2 \%$ & $76.0 \%$ & $57.7 \%$ & $<0.001$ \\
\hline 11 & $\begin{array}{l}\text { Patients should be en- } \\
\text { couraged to endure as } \\
\text { much pain as possible } \\
\text { before using an opioid. }\end{array}$ & $7.7 \%$ & $65.4 \%$ & $55.8 \%$ & $<0.001$ \\
\hline 12 & $\begin{array}{l}\text { Children less than } 11 \\
\text { years old cannot reliably } \\
\text { report pain so clinicians } \\
\text { should rely solely on the } \\
\text { parent's assessment of } \\
\text { the child's pain intensity. }\end{array}$ & $8.7 \%$ & $71.2 \%$ & $52.9 \%$ & $<0.001$ \\
\hline 13 & $\begin{array}{l}\text { After an initial dose of } \\
\text { opioid analgesic is given, } \\
\text { subsequent doses should } \\
\text { be adjusted in accordance } \\
\text { with the individual pa- } \\
\text { tient's response. }\end{array}$ & $30.8 \%$ & $88.5 \%$ & $64.4 \%$ & $<0.001$ \\
\hline 14 & $\begin{array}{l}\text { Giving patients sterile } \\
\text { water by injection (place- } \\
\text { bo) is a useful test to } \\
\text { determine if the pain is } \\
\text { real. }\end{array}$ & $39.4 \%$ & $80.8 \%$ & $60.6 \%$ & $<0.001$ \\
\hline 15 & $\begin{array}{l}\text { If the source of pain is } \\
\text { unknown, opioids should } \\
\text { not be used during the } \\
\text { pain evaluation period, as } \\
\text { this could mask the abil- } \\
\text { ity to diagnose the cause } \\
\text { of pain. }\end{array}$ & $7.7 \%$ & $71.2 \%$ & $57.7 \%$ & $<0.001$ \\
\hline
\end{tabular}

Table 3: Assessing Pain Knowledge Using Case Studies and Questions Questions (Percentages Pre-test Post- Followare based on the correct answers)

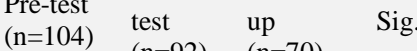

MCQ1: The recom-

mended route of admin-

istration of opioid anal-

gesics immediately after

$82.7 \%$

$58.7 \%$

$<0.001$

surgery.

MCQ2: The IV doses of

morphine that would be

equivalent to $30 \mathrm{mg}$ of

$11.5 \%$

$78.8 \%$

$55.8 \%$

$<0.001$

oral morphine.

MCQ3: Time to initial

3 analgesics administration

for post-operative pain.

MCQ4: Reason a patient

with pain would request

increased doses of pain

medication.

MCQ5: The source of

5 the most accurate judge

of the intensity of pain.

MCQ6: The time to peak

6 effect for morphine

given IV.

MCQ7: The time to peak

7 effect for morphine

given orally.

MCQ8: Manifestation of

physical dependence

Following abrupt discon-

tinuation of an opioid.

9 Case study 1: assessment

of pain level
Case study 2: assessment
of pain level

$7.7 \%$

$79.8 \%$

$59.6 \%$

$<0.001$

$34.6 \%$

$82.7 \% \quad 61.5 \%$

$<0.001$

$<0.001$

$5.8 \%$

$79.8 \% \quad 63.5 \%$

$<0.001$

$8.7 \%$

$79.8 \%$

$59.6 \%$

$<0.001$

$20.2 \%$

$81.7 \%$

$62.5 \%$

$<0.001$

$\begin{array}{llll}12.5 \% & 81.7 \% & 62.5 \% & <0.001 \\ 8.7 \% & 82.7 \% & 59.6 \% & <0.001\end{array}$

The total score of pain knowledge and attitude scale was calculated (Table 4). Chronbach's Alpa of the pre-test, post-test, and follow-up revealed acceptable values $(0.78,0.51$, and 0.59 , respectively). Mean of total score at the pre-test was low (6.25) compared to 21.80 at the immediate post-test and 20.79 at the followup. Therefore, a statistical significant difference between pre-test and post-test scores was noted $(\mathrm{p}<0.001)$ while no significant difference in means between post-test and follow-up scores $(p=0.667)$

Table 4: Total Pain Assessment Score

\begin{tabular}{cccccccc}
\hline $\begin{array}{c}\text { Total } \\
\text { score } \\
\text { (Range: } \\
\text { 0-25) }\end{array}$ & Number & Mean & SD & t & df & $\begin{array}{c}95 \% \text { Confi- } \\
\text { dence } \\
\text { Interval (CI) }\end{array}$ & Sig \\
\hline Pre-test & 104 & 6.25 & 4.14 & 33.172 & 91 & $14.62-16.49$ & $<0.001$ \\
$\begin{array}{c}\text { Post-test } \\
\begin{array}{c}\text { Follow- } \\
\text { up }\end{array}\end{array}$ & 92 & 21.80 & 1.72 & & & & \\
\hline
\end{tabular}

6.3. Comparing total scores to participants' demographics

A new variable was created to calculate the difference in total scores between the pre-test and post-test. Because the difference between post-test and follow-up was not significant, follow-up total scores were not used to compare changes. Although older participants scored higher in having knowledge and attitude toward pain at the pre-test phase, they showed the least improvement at the post-test compared to younger nurses (F: 10.721, df: 3 , $\mathrm{p}<0.001)$. Regarding gender, no significant difference found between male and female nurses in respect to the difference between pre-test and post-test (t 0.725 , df $90, \mathrm{p}=0.741$ ). Similarly, there was no any significant difference between professional degrees in regard to the difference between pre-test and post-test (F: 0.762 , df: 2, p=0.470). Regarding length of experience, participants who have a clinical experience of less than one years have showed 
higher improvement in means between pre-test and post-test compared to nurses with longer experience (F: 40.08, df: 2, p<0.001). Factors affecting knowledge and attitudes to pain management According to the above, age and length of experience were possible predictors to the successfulness of a brief pain education. The multiple-hierarchal regression was used to assess the effect of the both demographic variables in estimating the improvement of knowledge and attitude towards pain after such brief pain education. Regression model was developed through entering separate blocks (Table 5). The dependent variable was the newly created variable (difference between post-test and pre-test), and the independent variables were the age which was entered in the first block, and the clinical experience which was entered in the second block. The results of this model showed that around 30\% of the variance of total pain knowledge and attitude scores was explained by the age and length of experience.

Table 5: Summary of Regression Model

\begin{tabular}{|c|c|c|c|c|c|}
\hline Model & $\mathrm{R}$ & Adjusted R squared & F change & df & Sig. F change \\
\hline 1 & $.430^{\mathrm{a}}$ & .176 & 20.401 & 90 & .000 \\
\hline 2 & $.564^{\mathrm{b}}$ & .303 & 17.373 & 89 & .000 \\
\hline \multicolumn{6}{|c|}{ Predictors: (constant), Age } \\
\hline $\operatorname{Pr}$ & \multicolumn{5}{|c|}{ Predictors: (constant), Age, Experience } \\
\hline $\begin{array}{l}\mathrm{De} \\
\mathrm{mi}\end{array}$ & \multicolumn{5}{|c|}{ Dependant variable: Difference between pre-test and post-test (POST } \\
\hline
\end{tabular}

\subsection{Adherence to regular pain assessment}

The percentages of using pain assessment sheets to the number of admitted patients was increased from $10 \%$ (at the pretest level) to 92\% (eight months after the follow-up phase) as shown in Table 6. Increasing nursing adherence to pain assessment was also noted during the study period to reach $84 \%$ within three months.

Table 6: Adherence to Pain Assessment

\begin{tabular}{lll}
\hline Month & Completed sheet/total patients & Percentage \\
\hline $4 / 2013$ & $15 / 155$ & $10 \%$ \\
$5 / 2013$ & $54 / 340$ & $16 \%$ \\
$6 / 2013$ & $148 / 307$ & $48 \%$ \\
$7 / 2013$ & $338 / 460$ & $84 \%$ \\
$8 / 2013$ & $399 / 455$ & $87 \%$ \\
$9 / 2013$ & $533 / 637$ & $86 \%$ \\
$10 / 2013$ & $723 / 822$ & $87 \%$ \\
$11 / 2013$ & $683 / 821$ & $83 \%$ \\
$12 / 2013$ & $623 / 710$ & $88 \%$ \\
$1 / 2014$ & $631 / 698$ & $91 \%$ \\
$2 / 2014$ & $640 / 698$ & $92 \%$ \\
\hline
\end{tabular}

\section{Discussion}

This study showed that nurses' knowledge and attitudes towards pain in addition to their ability to assess pain effectively have shifted from negative to positive competency after receiving pain education. A previous study highlighted the knowledge deficits and negative attitudes of the nurses toward postoperative pain at the ordinary nursing compared to the positive improvement in the clinical competency regarding pain assessment and administration of analgesics after pain education as evidenced by higher KASRP tool score (17). While the difference in total knowledge scores between pre-test and post-test was significant, no significant difference was found between post-test and follow-up. This suggests that nurses have upgraded their knowledge of pain after pain education and they were able to sustain that higher level over a period of time.

These findings conform to a previous study which found that Chinese nurses have improved their pain knowledge following pain education and retained that level of knowledge for more than three months (Zhang, Hsu et al. 2008). Similarly, another study found that nurses' knowledge and attitudes toward pain management have improved after introducing a protocol for pain management (De Rond, De Wit et al. 2001). It is recommended that efforts to improve the quality of the pain management must be directed towards the implementation of such evidence-based guidelines which are widely acceptable in terms of safety and feasibility of pain management (Gordon, Dahl et al. 2005). As all nurses in this study claimed not receiving any previous pain training, professional training programs regarding pain management are required to enhance better understanding of the usefulness and application of pain assessment (Quinn and Hughes 2007). A previous study suggested that nurses were not confident about their knowledge of pain management because their basic education had not adequately prepared them to provide care for patients in pain (23). A recent survey of pain-related content in nursing curriculums worldwide found that in spite of acceptable nursing performance, school education in acute pain management is still inadequate (Vadivelu, Mitra et al. 2012). Similarly, a study of 16 American schools of nursing revealed that approximately $73 \%$ of the students claimed being taught about pain management; but only $36.5 \%$ believed that they were sufficiently prepared on this topic ((Fishman, Young et al. 2013).

This study found that younger nurses with shorter clinical experience were found more reactive with pain education compared to older nurses with longer clinical experience. A limited number of studies confirmed the relationships between the effectiveness of pain education and either nurse' age and length of experience. One study supported this result and found a negative correlation between age and NKASRP scores in which younger nurses with shorter clinical experience had a better adherence to the basic principle of pain management into practice (Machira, Kariuki et al. 2013). Another study found no significant differences in the mean total KASRP scores by age, education level, years of nursing experience and nurses with higher education levels had a weak positive correlation with KASRP scores (Moceri and Drevdahl 2014) However, Fothergill-Bourbonnais and Wilson-Barnett (28) concluded that clinical experience is the most influential factor that promotes nurses knowledge and confidence in managing patient's pain.

It was evident that a remarkable improvement in nursing adherence to regular pain assessment after the program had occurred. The number of pain assessment sheet used for hospitalized patients had increased from $10 \%$ to $92 \%$ over eight months of observation. This means that nurses become habitually committed to the pain assessment and aware to the importance of documenting pain response. This result support the premise that improving nurses' attitude to pain assessment would, in eventual, improve the adherence to pain assessment skillfully (Abed El-Rahman, Kalaldeh et al. 2013). A study (29) found the most significant barrier to effective pain management is nurses' reliance on their own subjective judgment (22). Another study found that 29 statements that describe pain assessment were subjective and inaccurate, and nurses reached their judgments based on their beliefs (19). Therefore, the implementation of pain education is regarded to increase nurses' adherence to pain assessment as it adds further values to the essence of pain management for hospitalized patients (De Rond MEJ, Campen BThM et al. 1999).

\section{Limitations of the study}

Absence of randomization and controlling to the study intervention would emaciate the validity of findings compared to welldesigned randomized-controlled trials. Study sample was restrained to one governmental hospital which may not be generalized to other heath care sectors in Jordan or even to other hospitals in the same sector.

\section{Conclusion}

The deficits and prejudices in pain management can be improved through implementing pain education programs. Nurses scored low in having knowledge and attitudes towards pain prior to pain education; whereas, a significant improvement in their knowledge and attitude after the delivery of a brief pain education was explic- 
it. It is viewed that commitment to ongoing pain assessment can be established through professional training and follow-ups for nurses working in the clinical field to introduce up-to-date pain measurement tools. Nurses' contribution to pain management with physicians is also recommended. Future research studies are invited to assess the impact of pain education program on a wider nursing population including different heath care sectors in Jordan.

\section{Acknowledgments}

We would like to acknowledge all nurses participated in the study including the active contribution of the quality assurance member at Ma`an governmental hospital/Jordan.

\section{References}

[1] Abed El-Rahman, M., A. Kalaldeh, et al. (2013). "Knowledge and attitude towards pain management. A comparison between oncology and non-oncology nurses in Jordan." International Journal of Ad$\begin{array}{llll}\text { vanced Nursing } & \text { Studies }\end{array}$ http://dx.doi.org/10.14419/ijans.v2i2.1006.

[2] Apfelbaum, J. L., C. Chen, et al. (2003). "Postoperative pain experience: results from a national survey suggest postoperative pain continues to be undermanaged." Anesthesia \& Analgesia 97(2): 534-540. http://dx.doi.org/10.1213/01.ANE.0000068822.10113.9E.

[3] Betty Ferrell, a. M. M. (revised 2012.). " "Knowledge and Attitudes Survey Regarding Pain” developed by." (http://prc.coh.org).

[4] Chanques, G., M. Sebbane, et al. (2007). "A prospective study of pain at rest: incidence and characteristics of an unrecognized symptom in surgical and trauma versus medical intensive care unit patients." Anesthesiology 107(5): 858-860. http://dx.doi.org/10.1097/01.anes.0000287211.98642.51.

[5] De Rond, M., R. De Wit, et al. (2001). "The implementation of a Pain Monitoring Programme for nurses in daily clinical practice: results of a follow-up study in five hospitals." Journal of Advanced Nursing 35(4): 590-598. http://dx.doi.org/10.1046/j.1365-2648.2001.01875.x.

[6] De Rond MEJ, D. W. R., Van Dam FSAM, Van, D. H. Y. Campen BThM, Klievink MA,, et al. (1999). "Daily pain assessment: value for nurses and patients.

[7] ." J Advanced Nursing; 29:436-444. http://dx.doi.org/10.1046/j.1365 2648.1999.00903.x.

[8] Dunwoody, C. J., D. A. Krenzischek, et al. (2008). "Assessment, physiological monitoring, and consequences of inadequately treated acute pain." Journal of PeriAnesthesia Nursing 23(1): S15-S27. http://dx.doi.org/10.1016/j.jopan.2007.11.007

[9] Fishman, S. M., H. M. Young, et al. (2013). "Core competencies for pain management: results of an interprofessional consensus summit." Pain Medicine 14(7): 971-981. http://dx.doi.org/10.1111/pme.12107.

[10]Fraser, G. L., J. W. Devlin, et al. (2013). "Benzodiazepine versus nonbenzodiazepine-based sedation for mechanically ventilated, critically ill adults: a systematic review and meta-analysis of randomized trials." Critical care medicine 41(9): S30-S38. http://dx.doi.org/10.1097/CCM.0b013e3182a16898

[11] Gordon, D. B., J. L. Dahl, et al. (2005). "American pain society recommendations for improving the quality of acute and cancer pain management: American Pain Society Quality of Care Task Force." Archives of Internal Medicine 165(14): 1574-1580. http://dx.doi.org/10.1001/archinte.165.14.1574.

[12]Herr, K., P. J. Coyne, et al. (2011). "Pain assessment in the patient unable to self-report: position statement with clinical practice recommendations." Pain Management Nursing 12(4): 230-250. http://dx.doi.org/10.1016/j.pmn.2011.10.002.

[13]Hirsh, A. T., M. P. Jensen, et al. (2010). "Evaluation of nurses' selfinsight into their pain assessment and treatment decisions." The Journal of Pain 11(5): 454-461. http://dx.doi.org/10.1016/i.jpain.2009.09.004.

[14]Jain, A., R. Yeluri, et al. (2012). "Measurement and Assessment of Pain in Children-A Review." Journal of Clinical Pediatric Dentistry 37(2): http://dx.doi.org/10.17796/jcpd.37.2.k84341490806t770

[15] Kastrup, M., V. von Dossow, et al. (2009). "Key performance indicators in intensive care medicine. A retrospective matched cohort study." Journal of International Medical Research 37(5): 1267-1284 http://dx.doi.org/10.1177/147323000903700502.

[16] Kehlet, H., T. S. Jensen, et al. (2006). "Persistent postsurgical pain risk factors and prevention." The Lancet 367(9522): 1618-1625. http://dx.doi.org/10.1016/S0140-6736(06)68700-X.
[17]Machira, G., H. Kariuki, et al. (2013). "Impact of an educational pain management programme on nurses pain knowledge and attitudes in Kenya." International journal of palliative nursing 19(7): 341-345. http://dx.doi.org/10.12968/ijpn.2013.19.7.341

[18] Moceri, J. T. and D. J. Drevdahl (2014). "Nurses' knowledge and attitudes toward pain in the emergency department." Journal of Emer$\begin{array}{lll}\text { gency } & \text { Nursing } & \text { 60(1): }\end{array}$ http://dx.doi.org/10.1016/i.jen.2012.04.014.

[19] Puntillo, K. A., C. White, et al. (2001). "Patients' perceptions and responses to procedural pain: results from Thunder Project II." American Journal of Critical Care 10(4): 238-251.

[20]Quinn, F. and S. Hughes (2007). "Quinn's Principles and Practice of Nurse Education Nelson Thornes." Cheltenham, England.

[21]Schafheutle, E. I., J. A. Cantrill, et al. (2001). "Why is pain management suboptimal on surgical wards?" Journal of Advanced Nursing 33(6): 728-737. http://dx.doi.org/10.1046/j.1365-2648.2001.01714.x.

[22] Twycross, A. (2007). "What is the impact of theoretical knowledge on children's nurses' post-operative pain management practices? An exploratory study." Nurse Education Today 27(7): 697-707. http://dx.doi.org/10.1016/j.nedt.2006.10.004.

[23] Vadivelu, N., S. Mitra, et al. (2012). "Acute pain in undergraduate medical education: an unfinished chapter!" Pain Practice 12(8): $663-$ 671. http://dx.doi.org/10.1111/j.1533-2500.2012.00580.x.

[24]Ware, L. J., P. Bruckenthal, et al. (2011). "Factors that influence patient advocacy by pain management nurses: Results of the American society for pain management nursing survey." Pain Management Nursing 12(1): 25-32. http://dx.doi.org/10.1016/j.pmn.2009.12.001.

[25]Zhang, C.-H., L. Hsu, et al. (2008). "Effects of a pain education program on nurses' pain knowledge, attitudes and pain assessment practices in China." Journal of pain and symptom management 36(6): 616627. http://dx.doi.org/10.1016/j.jpainsymman.2007.12.020. 